\title{
An Accountability Tool to Lose Weight, Prevent Weight Gain, and Prevent and Manage Obesity- Related Chronic Diseases
}

\author{
Ilana Muhlstein* \\ Department of Dietitian Nutritionist, Northeastern University, USA
}

Submission: November 16, 2016; Published: : January 24, 2017

*Corresponding author: Ilana Muhlstein, Department of Dietitian Nutritionist, Northeastern University, Beverly Hills, California, USA, Tel: (917) 767-2862; Email: ilanamuhlstein@gmail.com

\section{Introduction}

There is no denying the need for more effective weight loss intervention strategies in America where every single state has obesity rate of at least $20 \%$ and there is a growing prevalence of preventable obesity-related chronic diseases. Inexpensive, low intensity, practical, easily attainable strategies need to be included in weight loss intervention programs for greater outcomes. Every one kilogram of weight a person gains, equates to a $4.5-9 \%$ increase in diabetes risk and $3.1 \%$ increase in heart disease risk. Even a modest weight reduction of five to ten percent of a person's body weight can greatly improve his health and lower his risk and severity of a chronic disease. For instance, a five to ten percent weight loss was shown effective for reducing hemoglobin $\mathrm{A} 1 \mathrm{C}$ scores by half a point for people with diabetes, and lower triglycerides by $40 \mathrm{mg} / \mathrm{dl}$ and increase HDL (or good) cholesterol by 5 points. Therefore, it is essential that health professionals start making appropriate and effective recommendations to help people lose and control their weight.

Weight Watchers is a $\$ 1.4$ billion dollar company that is successful in getting hundreds of thousands of people to lose weight. Weight Watchers has been inconsistent with its approach and has changed their famous points system multiple times, going from "Points "to "Points Plus" to "Smart Points" in recent years. The only thing that consistently keeps Weight Watchers a successful and incredibly profitable weight loss program is accountability. Weight Watchers employs two accountability tactics to get people losing weight:

a) they make people go on the scale, and

b) they make people write down their food intake daily. Regardless of point's calculations, if people maintain a level of accountability, they will have a much easier time maintaining and controlling their weight. While people view food journaling as timely, confusing and impractical, the scale alone garners an immense amount of awareness over a person's dietary behaviors. The scale serves as a quick check-in or biofeedback tool that helps a person assess his health status.

Would a teenager ever study for a history test, if he never had a test? Of course not! Why would he? I always use this analogy when teaching my weight loss seminar at UCLA or working with a private client and encouraging them to use the scale, because it works very similarly. What difference does it make if you eat two cookies or four cookies, if you aren't planning on going on the scale for three months? None! However, if you see the difference on the scale in the morning, you would feel and internalize the difference, and be more likely to improve the behavior the next time you were offered cookies. Accountability in the form of going on the scale is proven effective for losing weight and keeping it off [1]. If there are no mile markers, it would be hard for a marathoner to strategize how to best run a race and see the finish line. Without midterms, quizzes, homework and finals, it would be nearly impossible for a teacher to understand how well a student absorbed the curriculum. If there were no dates in history, it would be hard to put all of the stories in context. This is why the scale is absolutely fundamental for successful weight loss and weight maintenance. With more than a third of America considered obese, it is critical that public health programs and campaigns are targeted towards getting people educated and access to home scales for greater self-awareness and understanding of how behaviors impact weight status. I have worked with hundreds of people for weight loss and never met two people who lose weight the same way.

That is the major fault of generic meal plans and fad diets; they try to create a one-size-fits-all model that doesn't work long-term. People need to lose weight on their own terms and schedules, and the scale helps create a personalized guide to 
achieve these goals. People always ask me "can I still eat chocolate once a week and lose weight?" and I say, "I don't know, you tell me!" Some things work for some people, and some things don't. My job as a dietitian is to be that support in helping a client use monitoring tools to effectively create an attainable and realistic individualized plan that works perfectly for him in reaching his goals. Everyone has the ability to create a perfect plan to control his weight, promote his health, and prevent chronic diseases, but it needs to be developed using accountability tools that show what works best for him and what doesn't.

\section{Discussion}

The Scale: Seeing Believes, Knowing and controlling how much weight could a person possibly gain in a three-day period? Even if a man went on an all-you-can eat binge for three days, he would still likely only be able to gain five pounds. And most adults have lost and gained five pounds many times in their lifetime and know it is achievable. But how about a month-long period without the scale? Or a year? Or 5 years?! That is typically when one becomes so terrified of what the scale might say that he either avoids it completely or goes on and see an uncomfortably high number that makes him feel defeated. People need to go on the scale at least twice a week for weight loss, and at least once a week for weight loss maintenance. As Kerri Boutelle [2], demonstrates so vividly, when a person engages in frequent weighing, he is empowered to quickly identify missteps in his progress and adjust his behaviors accordingly before spiraling further into a period of substantial weight gain.

Research supports the claim that people who weigh themselves more frequently can better manage their weight, in the short- and long-term. The National Weight Control Registry [3] is the largest prospective investigation of long-term successful weight loss maintenance and consists of over 10,000 members who have lost an average of about 66 pounds and kept it off for five and a half years. I am personally a member of this study, having lost over 90 pounds and kept it off for over eight years. The National Weight Loss Registry is an incredible source of research as it perfectly depicts how Americans can effectively challenge our destructive society and change our health status for the better. Interestingly, among those in this study who have maintained at least a $10 \%$ body weight loss for ten or more years, a whopping $77.4 \%$ weigh themselves at least once a week (35.6\% weigh themselves daily). Another study analyzing the behaviors amongst this group of successful weight losers and maintainers found that more frequent weighing was associated with lower body mass indexes (BMI) and less impulsivity and cognitive restraint around food. This highlights the added benefit of self-weighing in how it helps people think twice about their food intake as it pertains to their weight.

I feel as though people over think going on the scale and correlate it with a powerful emotional experience when it really just needs to serve as a quick health check-in. When a patient visits the doctor for a health exam, the doctor will typically weigh the patient before doing much else. Because just knowing a person's age, race, height, weight, and gender, a health professional can already asses his health and disease risk to a moderate degree. And just going on the scale at least once a week has been shown to maintain a better weight, and thus health, status over time. In a systemic literature review published in the International Journal of Behavioral Nutrition and Physical Activity, researchers found frequent self weighing to be consistent with a greater weight loss, weight maintenance, and lower body weight. The researchers found that weekly and daily self-weighers experienced a two to three point decrease in BMI, about 12-18 pound loss, compared to non-weighers. Going on the scale is such a small and simple act that contributes such a prominent impact in a person's weight and health condition.

Some studies further suggest daily weighing for best health results [4]. specifically examined daily self weighing by conducting a study with 91 overweight adults, whereby the experimental group used an internet-connected scale to weigh themselves daily for six months and see their weight changes graphed for them. The control group did not use the scale during those six months. In that time, the experiment group reported losing a statistically significant average of 13.8 pounds! Additionally, the participants reported eating fewer calories throughout the day and having a positive experience with the self weighing and suggested they would likely continue after the study. Self-weighing is completely straightforward and uncomplicated that when seen as an aforementioned painless "health check-in," it starts to become as elementary as brushing one's teeth: a little thing you do in the morning to ensure your body doesn't ruin later on. [5] proclaim that daily weighing is essential for combating an environment that is constantly promoting weight gain, such as an American college campus. Researchers in this study recruited thirty-four female freshmen at Cornell University and had the experimental group measure their daily body weight and email it each morning to the researchers for an entire semester. The untreated controls unfortunately gained 6.13 pounds during the semester, while the experimental group maintained their weight. These findings are precisely what I have concluded in working with clients seeking weight loss, when one does not check in periodically with the scale, especially in America's culture of energy dense junk foods and sedentary lifestyles, the scale always seems to creep up overtime [6]. Agrees that it is important that public health and clinical authorities promote daily weigh-ins for its strong benefit in aiding weight loss and preventing weight gain for the future. Because multiple studies have discovered that a behavioral change approach to weight loss will be key in curbing the growing prevalence of obesity and obesity-related chronic diseases in America, it is irresponsible to not promote daily weighing as a simple solution proven effective for weight loss.

And because it is undeniable that frequent self-monitoring in the form of self-weighing aids in weight loss, which can thus curb the deleterious obesity epidemic and staggering rates 
of preventable chronic diseases in America [7], aimed to see whether or not timing of weighing would help influence self control and restraint around food. While the researchers only found borderline significant correlations between restraint and weighing condition and found a slight change in subsequent food consumption, it is important that further research investigate this relationship for future intervention strategies using the scale as a tool to promote better dietary behaviors and a sense of accountability and sensibility with food. Health professionals have an obligation to promote this effortless and powerful function to promote weight loss and weight control. While the Centers for Disease Control and Prevention website recommend "monitoring your weight," they do now specify how often. I recommend that my clients seeking weight loss go on the scale at least Mondays and Fridays to determine what typically happens over the week days and what happens over the weekend to start determining patterns for the individual.

If somebody only goes on the scale once a week they may feel like they aren't losing any weight and be discouraged. However, if they went on more often, they would perhaps notice that they are losing two pounds during the week days, but gaining it back on the weekends, and should therefore target their efforts to planning more conscientiously for the weekends in the future. And in addition to recognizing patterns for more effective strategizing, the scale also provides incentive to eat healthier and more in line with weight loss goals. For example, if you know you are going on the scale Monday morning, you might reconsider that ice cream cone on Sunday afternoon. For these reasons, frequent weighing has proven incredibly effective in my personal 90-pound weight loss journey, as well as with my clients, and in the multiple studies as mentioned above.

\section{Conclusion}

It is too simple to say that it has only been a lack of going on the scale that has led to the obesity crisis in America. The staggering obesity rates have been attributed to a multitude of unhealthful behaviors such as increased television viewing, less sleeping, more junk food eating and promoting, and less physical activity, among many other factors. However, if people begin to monitor their weight as least bi-weekly, they will start to recognize these sabotaging and life-threatening lifestyle behaviors and take action to change them, rather than falling victims our reckless society. If one doesn't go on the scale for a long period of time and experiences a substantial weight gain, it will be hard for him to garner a sense of self-efficacy, which has been proven essential in several behavioral change theories. The transtheoretical model, self cognitive theory model and protection motivation theory all state self- efficacy as quintessential to making a health behavior change. Going on the scale makes people believe their efforts are worthwhile, which can help promote consistency.

If a person decides to eat healthy for three or four days, they are not necessarily going to feel an enormous boost of energy or find extra room in their clothes, but the scale will likely provide a sense of positive reinforcement to the change to help further foster healthy choices. Frequent self-weighing of at least one time per week is critical as a means of fulfilling the self-regulation theory of behavioral change. Going on the scale is truly fundamental for self-monitoring, personal accountability, and self-awareness to determine how behaviors impact weight. While self-weighing has been seen effective as a tool in a successful weight loss journey, it is certainly not the only thing needed to change America's current health crisis. More accountability measures such as daily food intake logs and counseling sessions with a registered dietitian and an exercise instructor have been long associated with more positive weight loss results as well. A greater degree of nutrition education, access to healthier foods, and increased mobility would similarly make strong improvements in the weight and health status of Americans. However, this report serves to highlight the need for frequent self-weighing to be included as an intervention strategy key in repressing the obesity crisis. [8-19].

\section{References}

1. Keeping It Off (2015).

2. Boutelle K (2006) Letters to the Editor. Journal of Nutrition Education and Behavior 38(3): 131.

3. The National Weight Control Registry.

4. Steinberg DM, Tate DF, Bennett GG, Ennett S, Samuel-Hodge C, et al. (2013) The efficacy of a daily self-weighing weight loss intervention using smart scales and email. Obesity 21(9): 1789-1797.

5. Levitsky DA, Garay J, Nausbaum M, Neighbors L, Dellavalle DM (2006) Monitoring weight daily blocks the freshman weight gain: A model for combating the epidemic of obesity. Int J Obes 30(6): 1003-1010.

6. Linde JA, Jeffery RW, French SA, Pronk NP, Boyle RG (2005) Selfweighing in weight gain prevention and weight loss trials. Ann Behav Med 30(3): 210-216.

7. Pacanowski CR, Bertz F, Levitsky DA (2014) Daily Self-Weighing to Control Body Weight in Adults: A Critical Review of the Literature. SAGE Open 4(4): 1-16.

8. Adult Obesity Prevalence Maps (2016).

9. Mokdad AH, Bowman B, Engelgau MM, Vinicor F (2001) Diabetes Trends Among American Indians and Alaska Natives: 1990-1998. Diabetes Care 24(8): 1508-1509.

10. Pietrzykowska NB (2016) Benefits of 5 to10 Percent Weight-loss.

11. Weight Watchers International, Inc. (2014) Form 10-K 2013.

12. Our Approach (2016).

13. Adult Obesity Facts (2016).

14. Thomas JG, Bond DS, Phelan S, Hill JO, Wing RR (2014) Weight-Loss Maintenance for 10 Years in the National Weight Control Registry. Am J Prev Med 46(1): 17-23.

15. Butryn M, Phelan S, Hill J, Wing R (2007) Consistent Self-Monitoring of Weight: A Key Component of Successful Weight Loss Maintenance. Obesity 15(12): 3091-3096.

16. VanWormer JJ, French SA, Pereira MA, Welsh EM (2008) The Impact of Regular Self-Weighing on Weight Management: A Systematic Literature Review. Int J Behav Nutr Phys Act 5(1): 54. 
17. Pacanowski CR, Sobal J, Levitsky DA, Sherwood NE, Keeler CL, et al. (2015) Does measuring body weight impact subsequent response to eating behavior questions. J Am Coll Nutr 34(4): 199-204.

18. Soleymani T, Daniel S, Garvey WT (2015) Weight Maintenance: Challenges, Tools and Strategies for Primary Care Physicians. Obesity Reviews 17(1): 81-93.
19. Lenzi A, Migliaccio S, Donini L (2015) Multidisciplinary Approach to Obesity: From Assessment to Treatment. ( $1^{\text {st }}$ edn), Springer International Publishing.
This work is licensed under Creative Commons Attribution 4.0 License

DOI: 10.19080/NFSIJ.2017.02.555579
Your next submission with Juniper Publishers will reach you the below assets

- Quality Editorial service

- Swift Peer Review

- Reprints availability

- E-prints Service

- Manuscript Podcast for convenient understanding

- Global attainment for your research

- Manuscript accessibility in different formats ( Pdf, E-pub, Full Text, Audio)

- Unceasing customer service

Track the below URL for one-step submission https://juniperpublishers.com/online-submission.php 